\title{
Effect of Affective Priming on Prosocial Orientation through Mobile Application: Differences between Digital Immigrants and Natives
}

\section{Francesca D'Errico* \& Marinella Paciello**1, Roberta Fida***, Carlo Tramontano****}

*Università Roma Tre, Dipartimento di Filosofia, Comunicazione e Spettacolo. Via Ostiense 234, 00146 Roma, Italy; francesca.derrico@uniroma3.it

** UNINETTUNO University, Corso Vittorio Emanuele II, 39, 00186 Roma, Italy; m.paciello@uninettunouniversity.net

*** Norwich Business School, University of East Anglia, Thomas Paine Study Centre 1.27, NR4 Norwich, United Kingdom; r.fida@uea.ac.uk

**** Centre for Research on Psychology, Behaviour, and Achievement, Coventry University, Priory Street Coventry, CV1 5FB Coventry, United Kingdom;

carlo.tramontano@coventry.ac.uk

\begin{abstract}
Digital revolution has drastically changed people's lives in the last three decades inspiring scholars to deepen the role of technologies in thinking and information processing (Baranyi et al., 2015). Prensky (2001) has developed the notion of digital generation, differentiating between natives and immigrants. Digital natives are characterised by their highly automatic and quick response in hyper-textual environment. Digital immigrants are characterised by their main focus on textual elements and a greater proneness to reflection. The main goal of the present research is to investigate the effect of affective priming on prosocial orientation in natives and immigrants by using a mobile application. A quasi-experimental study has been conducted to test whether and how the manipulation of the priming, through positively and negatively connoted images, influences prosocial orientation. The results attested that negative affective priming elicited by app influences negatively prosocial orientation, while positive affective priming influences it positively prosocial orientation. However, this effect is true mainly for digital natives. Overall, findings underline the relevance of taking into account the effects of affective priming in technological environment, especially in the case of digital natives.
\end{abstract}

Keywords: prosocial orientation; affective priming; mobile application; digital generation; quasi-experimental study

The authors wish it to be known that, in their opinion, the first two authors should be regarded as joint First Authors 


\section{Introduction}

The present contribution can be included within the Cognitive Infocomm research field (Baranyi \& Csapó, 2012).) that studies cognitive processes which operate when humans interact with ITC. In particular our study deals with Affective Computing (Picard, 2003) and Social Signals Processing (Vinciarelli et al., 2011) research fields, the study is aimed at examining the role played by the visual cues (positively and negatively connoted images) and related emotions (positively and negatively affectivity) in priming the behavioral orientation through a mobile application. Specifically, following this approach which underlined how emotions are intimately linked with cognitive processes, the study aims to observe the potential impact of affective images on individuals prosocial behavioral orientations. Moreover, considering that the 'digital revolution' has not only significantly transformed people's lives and practices, but it also divides generations depending on their modality of interaction with new media, differences across generations were examined. Prensky (2001a) distinguished between digital natives and digital immigrants and highlighted their different cognitive functioning when interacting with technologies. Specifically, the former are those exposed to technologies either since they were born or early in their development, and in general, they are characterised by their highly automatic and quick response in a hyper-textual environment. In contrast, the latter acquired the use of technologies as youth or as an adult, and in general, they are characterised by their greater proneness to reflection and preference for textual reading (Jenkins Purushotma, Weigel, Clinton, \& Robison, 2009). Although the differences between natives and immigrants in their different modalities in using technology have been largely discussed in the literature (Palfrey \& Gasser, 2008; Prensky, 2001b, 2009), the great majority of the studies examining psychological variables in technological environments focus attention mainly on youth. As a result, differences associated with a potential difference in familiarity with the new languages of communication have been disregarded. For instance, it is acknowledged that technological environments are characterised by different combinations of text, images, and sensorial stimuli conveying positive and/or negative information that may activate affective processes (i.e., affective priming) in users (Norman, 2004). However, it is not clear whether the influence of such stimuli could be different between digital natives and immigrants.

Based on these premises, in this contribution, we aim to compare the role of affective priming activated by a mobile app on prosocial orientation between digital natives and immigrants. The role of affectivity in directing prosocial behaviour has been largely recognised (Carlson \& Miller, 1987; Shaffer \& Graziano, 1983); however, this has been overlooked in technological environments. Overall, others' needs for help may activate positive (e.g., pride, tenderness, or joy) or negative (e.g., personal distress, disgust, or anger) affective states that may, respectively, make it easier to help (Carlson, Charlin \& Miller, 1988; Rosenhan, Salovey, Karylowski, \& Hargis, 1981) or more difficult, 
especially when personal costs are at stake (Batson, Fultz, \& Schoenrade, 1987; Paciello, Fida, Cerniglia, Tramontano, \& Cole, 2013). However, what happens when prosocial orientation is examined within an emotionally connoted technological environment? Is prosocial orientation within technological environments different across generations? Specifically, do digital natives and immigrants show different prosocial orientation across positive or negative affectively connoted technologies? To address these questions, this contribution will test whether and how affective priming activated by a purposely developed mobile app affects prosocial orientation in digital native and immigrants through a preliminary study and a main quasi-experimental study.

\section{Digital Immigrants vs Digital Natives}

Given the acceleration of the technological development in the last three decades, resulting in continuous updates and the constant rise of tools and media, it is important to consider that a user's age tends to be related to their specific digital 'literacy' (Jenkins, 2006, Jenkins et al., 2009; Prensky, 2001a). This led to the suggestion of the possibility of differentiating individuals depending on the 'digital generations' to which they belong. Unlike previous generations, technology provides individuals in the last decades with a massively broader explorative 'area', which could affect, at least to some extent, the process of their identity construction. Indeed, very often this new generation tends to show 'fluid identity', which comes from the fusion of real and virtual experiences and is characterised by high flexibility (Gardner \& Davis, 2013). Prensky (2001b) described digital natives as equipped for managing parallel and multitasking processes mainly based on visual images, characterised by graphics awareness, multidimensional visual-spatial skills, attentive deployment in multiple locations simultaneously, and fast responses to expected and unexpected stimuli. In summary, they have hyper-text minds that tend to surf through images and videos to discover new sources of information and to share content with friends. In addition, Jenkins and colleagues (2009) highlighted how the most frequent methods to acquire and produce information are 'multitasking', 'mash up', and 'remix' based on attractive external stimuli or more in general 'outward-facing, and constrained by the programming decision of the app designer' (Garder \& Davis, 2013; p. 60). Alternatively, digital immigrants tend to be sequential, mainly focused on textual elements and more characterised by a greater proneness to reflection and metacognition (Ferri, 2011; Gardner \& Davis, 2013; Jenkins et al., 2009). Prensky (2009) also differentiated between digital skills and digital wisdom, suggesting that, while digital natives tend to have higher skills but a lower capability to use them in a positive and wise way, the opposite pattern tends to be true for digital immigrants. More recently, Gardner and Davis (2013) developed a new label akin to digital natives. Specifically, they introduced the 
term generation apps meaning a 'packaged identity' focused on specific technical skills based on contextual stimuli. External appearance is central to them, and their identity is mostly rooted in quantifiable indicators (e.g., expressing and counting 'likes' on posts and photos or comments on social networks), while other or community-oriented goals are considered less relevant. This 'self-centred identity' is strongly linked to the notion of self-presentation. Indeed, digital natives learn from the first stage of their life to express their emotions and identity by means of 'selfies' that allow them to exhibit their own self to be immediately shared with others through instant messaging apps. This generation tends to use apps for sharing photos and videos sometimes with a strict and quick expiring time (as in the case of Snapchat), reinforcing the idea that self-presentation implies optimal 'performance' (Gardner and Davis 2013) where, for instance, formal and aesthetic features need to be maximised.

Following Gardner and Davis (2013), it is likely that digital natives (or generation apps) are also characterised by a lower prosocial orientation than that of digital immigrants in technologically mediated environments. However, to the best of our knowledge, no previous studies have empirically tested digital generation differences in prosocial orientation, despite the importance of promoting this kind of behaviour in both natives and immigrants. Indeed, prosocial behaviour is a good predictor of positive social adjustment, of civic and moral responsibility, and of inclusive participation.

\section{Prosociality in Technologically Mediated Contexts}

Within the literature on information technology communication and potentially even on Cognitive Infocommunications (CogInfoCom; Baranyi et al., 2015), prosocial behaviour has been used in different prosocial media that are technological devices strategically created to promote this kind of behaviour (i.e., virtual games, social networking, and more recently in apps) (Gentile et al., 2009). For instance, in a longitudinal study, Prot (2014) showed how prosocial video games can contribute to increasing empathy and helping behaviour among adolescents across different cultures. This 'prosocial effect' has been further supported by Greitemeyers and Osswald (2009), highlighting that the more that games are sophisticated and emotionally involving, the greater the promotion of prosocial conduct, assessed in terms of reaction times to prosocial words. Finally, Cohen (2014) studied 'serious narrative digital games' and underlined that they may promote positive emotions, and in turn, the sharing of positive messages about social causes. Prosocial behaviour in social networks has been particularly investigated in two studies. Wright and Li (2012) underlined the association between online and off-line prosocial behaviour, and Shin, Lee and Kim (2015) showed that social presence, in terms of visibility, and other contextual factors related to different degrees of normativeness could promote prosocial intentions 
and activities among university students. Prosocial apps have also been developed for different social campaigns and causes. A pioneering example is the Nostalgia interface, aimed to facilitate networking between elderly people in England with the aim of providing reciprocal support (Nilsson, Johansson, \& Håkansson, 2003). A more recent example is the UNICEF Tap Project ('UNICEF' App, 2014), an app developed to gather information and updates as well as sustain UNICEF activities through donations and/or involvement in volunteering activities.

Overall, although a growing body of research is focusing attention on the relationship between technologies and prosocial behaviour, underlining the relevance of affective activation of the users, empirical evidence on the use of apps in mobile devices is still very preliminary. Furthermore, the aforementioned studies have been invariably implemented on young participants who, in the most recent years, are likely to be assimilated to digital natives, leaving the effect of technologies in digital immigrants quite unexplored.

\section{Affective Dimensions of Prosociality and Technologies}

The affective relevance of technologies has been studied within human computer interaction (HCI) and social robotics to build affective and empathic interfaces and technologies in dialogue with humans. Norman (2004) emphasised the role of affordance as an external sensorial feature (visual, tactile, auditory, and so on) of a technology that can produce pleasure or displeasure or, more in general, positive or negative affect. Specifically, when interacting with an app, a website, or a technology, the user can undergo an emotional experience elicited by external features that indeed act as affective priming. Affective priming refers to the automatic relevance of different sensorial stimuli that can activate consistent polarised individuals' affective states, influencing their perceptions, judgements, and behaviour (Chen \& Bargh, 1997; Greewald, Draine, \& Abrams, 1996; Klauer $\&$ Musch, 2003). Some examples are smiling vs angry faces, round vs sharp objects and shapes, bright vs deep colour tones, and peaceful vs exciting music. Hence, affecting priming can be negatively or positively oriented, correspondingly resulting in positive or negative emotions, such as in the case of a scene of danger that elicits a fearful emotional state and can be associated with a set of consistent negative memories (Bower, 1981).

According to previous studies on affective priming, while negative emotional states can promote more systematic information processing and less proactive reactions, positive affective state results in the opposite pattern (Forgas, 2007; Sinclair \& Mark, 1995). This emotional dynamic can provide a rationale to understand prosocial orientation within technological contexts, where there is a wide variety of sensorial stimuli potentially resulting in affective priming. 
This priming can affect prosocial orientation in various ways. For example, images can play a pivotal role. Indeed, Bebko, Sciulli, and Bhagat (2014), echoing Burt and Strongman's findings (2005), observed, through eye-tracking that the emotional activation raised from specific content of social advertisement images (e.g., a smiling face) is associated with a greater emotional response and, in turn, resulted in higher donation. Further research has suggested that the positive emotional activation elicited by images of flourishing futures also have an effect on participation in social causes as opposed to negative emotions raised from negative prospective scenarios (Lennon \& Rentfro, 2010).

It must be acknowledged that there are also studies suggesting a rather different relationship between affective activation and prosocial behaviour. Tan and Forgas (2010), in particular, showed that while positive mood tends to increase selfishness, negative mood tends to result in fairness and donations. However, this specific study was based on a particular economic task named 'dictator game' in which participants must also consider their personal economic benefit, as a counterbalance of donations to others. Hence, in this case, the donation is not a pure prosocial behaviour, but it is the result of a cold cost-benefit calculation. To understand the relationship between affective priming and prosocial behaviour, it is important to consider the costs associated with different types of support (D'Errico, Leone, \& Poggi, 2010; Leone, 2012; Nadler, 2012). For example, a 'remote' donation of money does not imply the same level of involvement and emotional activation as donating one's own time in a critical real situation. This effect is further clarified by the experiment conducted by Skandrani-Marzouki, Marzouki, and Joule (2012) in which affective priming (manipulated by means of happy vs angry faces) influences helping behaviour (assessed in terms of time devoted to volunteering activities). Specifically, positive affective priming is associated with greater helping behaviour, while negative affective priming is associated with lower helping behaviour (for a review on the relationship between affect and prosocial behaviour, see Bieroff, 2008; Isen, 2000).

Overall, the existing literature provides evidence and support of the relationship between affective priming and prosocial orientation in a technologically mediated environment, although the results are not yet conclusive and consistent particularly in relation to the role of negative affectivity and of the perceived personal costs associated with the potential engagement in a specific form of prosocial conduct.

\section{Present Research}

The main goal of the present research is to investigate the role of affective priming on prosocial orientation in digital natives and immigrants. Our research questions were as follows: 
Question 1: Can the affective priming elicited by an app (via mobile device) influence prosocial orientation? In line with the literature (Isen, 2000; SkandraniMarzouki et al., 2012), pointing out how positive affect induces greater prosocial behaviour than negative affect, we hypothesised that the positive priming will result in a higher level of prosocial orientation, while the negative priming will result in a lower level of prosocial orientation.

Question 2: Can differences between digital natives and digital immigrants be a crucial variable for being affected by (positive vs negative) priming? How can this influence promote different prosocial orientations? Since digital natives can be more attracted by visual stimuli presented in technological devices (Gardner \& Davis, 2013; Presky, 2001b), it is plausible to hypothesise that they will be more subject to the effect of affective priming than immigrants. Thus, they will be more prone to be prosocially oriented in positive priming condition and less prone in negative condition.

To address these research questions and to test our hypotheses, we apply the affective priming paradigm using visual stimuli via an app developed ad hoc for this research. In the method section, we will present: 1) a preliminary study aimed to identify and validate priming stimuli affectively connoted as positive vs negative, and 2) a quasi-experimental study aimed to test whether and how the experimental manipulation (positive vs negative vs neutral conditions) affects prosocial orientation.

\subsection{Method}

\subsubsection{Preliminary Study}

The aim of this preliminary study was to identify the images to be used in the quasi-experimental study on the role of affective priming in influencing prosocial orientation. Images have been identified by three experts on prosocial behaviours considering two features: content and affective valence. Specifically, all images were expected to show situations in which the need for help was evident and that could potentially activate three different kinds of prosocial behaviour: helping, sharing, and caring. Regarding the affective valence, images were expected to activate positive or negative affective reactions. Specifically, negative images should have represented situations in which a helpee was alone, a high personal cost for a helper was a stake (e.g., dramatic or perceived dangerous situations), and the helpee expressed high levels of negative emotions (e.g., presence of high distress). In contrast, positive images should have represented situations in which a helpee was supported by others, there was low personal cost for a helper (e.g., supporting behaviours between two friends), and the helpee expressed positive emotions (e.g., presence of relief). 


\subsubsection{Priming Stimuli}

As a result of the first step, the experts identified 24 non-copyrighted images as priming stimuli. Further to the above-mentioned criteria, the experts also followed Norman's suggestions (2004) to classify images as positive or negative, specifically considering the presence or absence of colours (black and white or vividly coloured images) and facial expression (positive or negative emotions). Overall, negative images were black and white images describing negative situations where the person was in extreme state of need, left alone while expressing negative emotions (sadness, fear, or anxiety). Positive images instead were coloured pictures describing positive situations in which the person in need is supported and expressed positive emotions (relief, joy, or gratitude; see Fig. 1).

Figure 1

Example of visual priming stimuli

Positive Images

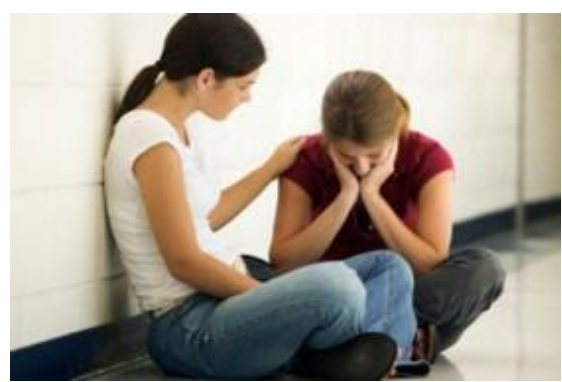

Negative Images

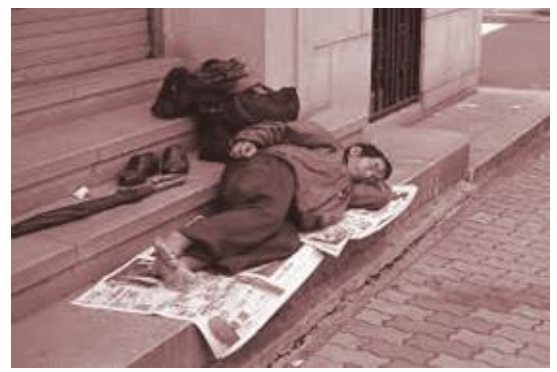

\subsubsection{Sample and Procedure}

Twenty-six university students $(58 \%$ females, mean age $=37.2, \mathrm{SD}=12.5)$ attending an online undergraduate module in cognitive psychology were invited to participate in an online survey. Specifically, for each of the images identified, participants were asked to associate a word with each image (semantic dimension), classify it as positively or negatively connoted (affective polarity), and rate the intensity of their emotional activation (affective intensity).

Before starting, on the class web-forum, a researcher explained the study procedures and was available for dispelling any possible doubts. All students gave their informed consent to participate. At the end of the data collection, the students received feedback on their responses and they were invited to discuss on the relationship between images and affect collectively with the researcher. 


\subsubsection{Measures}

Semantic dimension was assessed by asking participants to freely associate a word with each image.

Affective polarity was assessed by asking participants to classify priming stimuli as positively or negatively connoted. Affective intensity was assessed by asking participants to rate the level of affective intensity related to each image on a 10point scale $(1=$ very low intensity to $10=$ very high intensity $)$.

\subsubsection{Data Analyses}

To examine whether each image was positively or negatively connoted, a semantic analysis was undertaken on freely associated words, specifically, using the lexicographic approach (Lebart, Lebart, L., Salem, \& Berry, 1998), and the frequencies of the words associated with each picture was analysed. A chi-square test was used to verify the congruence between the polarity (positive vs negative) evaluated by the students (empirical responses) and the expected polarity (theoretical classification). To test whether the positive and negative images were similarly activated, we implemented a t-test on the mean intensity rating.

\subsubsection{Results}

Results from the semantic analysis are presented as word clouds in Figure 2. This analysis suggested the differentiation between two aspects: one related to different kinds of prosociality and states of need, while the other is related to emotions. Specifically, the findings showed that, in relation to the positive images, participants significantly mentioned $(\mathrm{p}<0.05)$ words like sharing, generosity, support, help, and care (from the helper point of view), while, for the negative images, they significantly associated words $(\mathrm{p}<0.05)$ like poverty, needs, and abandon (mainly oriented toward the helpee's state of need). As to the emotions in positive priming, the most frequent emotions cited $(\mathrm{p}<0.05)$ were: friendship, trust, happiness, tenderness, love, and relief, while, in the negative priming, tiredness, boredom, pain, suffering, and depression were cited.

Results of the chi-square showed a significant association between the theoretical and empirical classification of the stimuli $\left(\chi^{2}=239.86 ; \mathrm{p}<.01\right)$. Specifically, both for the positive and negative images, the theoretical and empirical classifications were significantly associated (Table 1), attesting to the adequacy of the images identified by the experts to be used in the quasi-experiment.

The intensities reported for positive vs negative images did not significantly differ, as attested by the t-test [t(37) $=.39, \mathrm{p}=.693]$. In particular, intensity is particularly high for both positive (ranging from 3 to 8.70 ; mean $=7.11$, SD $=1.40$ ) and negative images (ranging from 1 to 8.68 ; mean $=7.02, \mathrm{SD}=1.76$ ). 
Figure 2

Words-clouds for positive and negative priming stimuli

Positive Stimuli

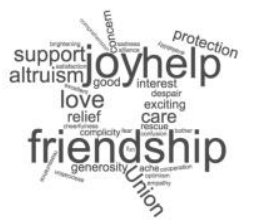

Negative Stimuli

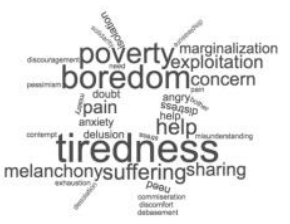

Table 1

Priming stimuli classification

\begin{tabular}{|c|c|c|c|c|}
\hline & & \multicolumn{2}{|c|}{ Empirical classification } & \\
\hline \multirow{4}{*}{ 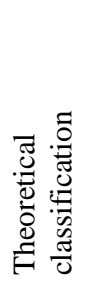 } & \multirow[b]{2}{*}{ Positive Stimuli } & Positive Affectivity & $\begin{array}{l}\text { Negative } \\
\text { Affectivity }\end{array}$ & $\begin{array}{l}\text { Marginal } \\
\text { Row Totals }\end{array}$ \\
\hline & & $263(84.3 \%)$ & $49 \quad(15.7 \%)$ & 312 \\
\hline & Negative Stimuli & $70 \quad(22.4 \%)$ & $242(77.6 \%)$ & 312 \\
\hline & $\begin{array}{l}\text { Marginal Column } \\
\text { Totals }\end{array}$ & 333 & 291 & 624 \\
\hline
\end{tabular}

\subsubsection{Discussion}

Results of this preliminary study confirmed the goodness of the priming stimuli selected for the quasi-experiment, as supported by the significant association between the classifications of the experts and participants. The polarity of the affective priming is also confirmed by the qualitative analysis. Specifically, positive images characterised by the presence of support and positive feelings between the helper and helpee activated emotions like joy, love, and relief and were semantically associated with help, friendship, union, and protection. The negative images characterised by the absence of support and high distress activated emotions like pain, anxiety, and boredom and were semantically associated with poverty, suffering, marginalisation, and isolation. Furthermore, the results indicate that the selected images were not neutral but were affectively connoted, and both positive and negative images highly affectively primed participants. 


\section{Main Study}

The main study was aimed to examine whether positive and negative affective priming - activated by the images selected in the preliminary study - were associated with different prosocial orientation assessed using a mobile application. As anticipated, in line with the literature (Isen, 2000; Skandrani-Marzouki et al., 2012), we expected that positive and negative activation can positively or negatively influence prosocial orientation. In addition, we also aimed to investigate the possible differences between digital natives and immigrants in affective priming on prosocial orientation.

\subsubsection{Participants and Procedure}

Participants were enrolled in a quasi-experimental study using an application on a mobile device (tablet or smartphone) to assess individual prosocial orientation. Overall, 299 individuals (72\% female) participated. They were from Europe (42\%) and North America (58\%), with a mean age of 33 years $(\mathrm{SD}=10.7$, ranging from 18 to 60$)$.

The digital natives and immigrants were identified based on their age: natives were participants under 30 years of age $(\mathrm{N}=124$, mean age $=22.3, \mathrm{SD}=4.0)$, and immigrants were people over 30 years of age $(\mathrm{N}=175$, mean age $=40.6, \mathrm{SD}=$ $6.9)$.

All participants voluntarily took part in the study and provided their consent (via the app) before starting the quasi-experiment. They were free to stop the procedure at any time, if they chose to do so. The research was previously approved by the Ethical Committee of the first author's faculty and was monitored by a software developer together with the authors.

\subsubsection{Experimental Design}

The quasi-experimental study has a factorial between subjects design with two independent variables. The first corresponds to the manipulation of the affective priming (positive vs negative vs neutral control conditions), and the second is the type of digital generation (digital natives vs immigrants). In addition, gender and country (Europeans vs North Americans) were included as control variables. The dependent variable is the prosocial orientation.

Priming conditions were created by manipulating the presentation of 12 prosocial items selected from the original scale developed by Caprara and colleagues (Caprara, Steca, Zelli, \& Capanna, 2005). These items were associated with three possible conditions: 1) neutral, without images; 2) negative priming, in which prosocial items were associated with negative affective images; and 3) positive priming, in which prosocial items were associated with positive affective images. 
The three conditions were implemented using the 'Prosociality' mobile application (available on the Google Play Store) that randomly assigns participants to negative, positive, or neutral conditions.

\subsubsection{Measures}

The participants were asked to rate 12 items assessing prosocial orientation on a 5point scale (ranging from $1=$ never to $5=$ almost always). The scale provides the score in one dimension (Cronbach's alpha $=.87$ ). However, since the items refer to helping (4 items; e.g., 'I try to help others'), sharing (4 items; e.g., 'I share the thing that I have with others'), and caring ( 4 items; e.g., 'I try to console those who are sad'), the three corresponding sub-scores were computed and considered in the following analyses as well. Cronbach's alphas were .72, .68, and .75, respectively.

\subsubsection{Data Analyses}

Preliminarily, subject distribution in the three priming conditions was examined. Then, to study the priming effect on prosocial orientation, we used a 3 (priming conditions) x 2 (generations: digital natives vs digital immigrants) analysis of covariance (ANCOVA) factorial design, controlling for countries (Europe vs North America) and gender. The condition levels represent the assignment of participants to one of the three conditions: neutral, positive affective priming, or negative affective priming. The priming effect was examined on total prosocial orientation and then on the three sub-scores (helping, sharing, and caring). In case of significant effects, we implemented multiple pairwise comparisons using Bonferroni corrections.

\subsubsection{Results}

The responses in the three priming conditions across digital generations were balanced, as indicated by a not significant chi-square $[\chi 2(2)=2.19 ; \mathrm{p}=.334)]$. Results of the ANCOVA, considering the overall prosocial orientation score, attested to the significant effect of the priming condition $[\mathrm{F}(2,298)=4.06, \mathrm{p}<.05$; $\eta 2=.03]$ and the interaction between digital generations and the priming condition $[\mathrm{F}(2,298)=3.99, \mathrm{p}<.05 ; \eta 2=.03]$. The main effect of the digital generation was not significant $[\mathrm{F}(2,298)=3.03, \mathrm{p}=.08]$. The results of the pairwise comparisons showed that the levels of prosocial orientation were lower in the negative affective priming condition than in the positive affective priming condition, controlling for both gender and country, and that the levels of prosocial orientation in the control group were not different in both positive and negative conditions (Table 2). 
Table 2

Observed means and standard deviations of prosocial orientation in priming conditions across digital generations

\begin{tabular}{|c|c|c|c|c|c|c|c|c|}
\hline & $\begin{array}{l}\text { Positive } \\
\text { Priming }\end{array}$ & & $\begin{array}{l}\text { Neutral } \\
\text { Condition }\end{array}$ & & Negative & Priming & Total & \\
\hline & Mean & SD & Mean & SD & Mean & SD & $\begin{array}{l}\text { Mea } \\
n\end{array}$ & SD \\
\hline Native Digitals & 3.91(a) & .63 & $3.56(\mathrm{ab})$ & .85 & $3.32(\mathrm{c})$ & .67 & 3.61 & .75 \\
\hline Digital Immigrants & 3.73 & .64 & 3.73 & .70 & 3.71 & .57 & 3.72 & .64 \\
\hline Total Sample & 3.81(a) & .64 & $3.67(a b)$ & .76 & $3.54(b)$ & .64 & 3.68 & .69 \\
\hline
\end{tabular}

Note: Different letters indicate significant differences across priming conditions

With regard to the interaction between priming conditions and digital generations, the pairwise comparison indicated that the difference in the prosocial orientation between negative and positive conditions was significant only for the native group (Figure 3).

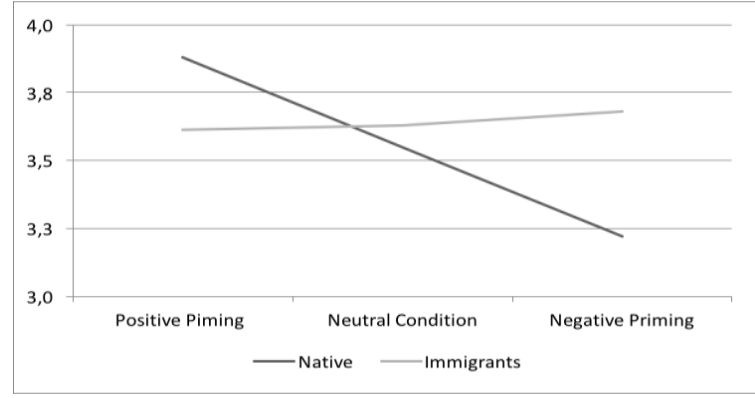

Figure 3

Prosocial orientation in priming conditions across digital generations

Results of the ANCOVA on the three different forms of prosocial behaviours (sharing, helping, and caring) attested that the main effect of the priming conditions was significant for both caring $[\mathrm{F}(1,287)=3.61 \mathrm{p}<.05, \eta 2=.02]$ and sharing $[\mathrm{F}(1,287)=3.15 \mathrm{p}<.05, \eta 2=.02]$ but not for the helping subscale $[\mathrm{F}(1$, $287)=2.61 \mathrm{p}=.07]$. The results confirmed that the participants in the positive priming conditions scored higher in both caring and sharing, controlling for both gender and country. However, the levels of prosocial behaviour in the control group were not different for both positive and negative conditions (Table 3). Furthermore, the main effect of digital generation was significant for helping $[\mathrm{F}(1$, $287)=4.29 \mathrm{p}=.04, \eta 2=.01]$ and sharing $[\mathrm{F}(1,287)=4.44 \mathrm{p}=.04, \eta 2=.01]$, confirming that immigrants tend to be more oriented toward others (Freund \& Blanchards-Fields, 2014). 
Table 3

Observed means and standard deviations of helping, sharing and caring orientation in priming conditions across digital generations

\begin{tabular}{llllllll}
\hline & & \multicolumn{2}{c}{ Helping } & \multicolumn{3}{c}{ Sharing } & \multicolumn{2}{c}{ Caring } \\
Positive & Natives & $3.95(\mathrm{a})$ & .70 & $3.93(\mathrm{a})$ & .71 & $3.84(\mathrm{a})$ & .75 \\
\cline { 3 - 7 } Priming & Immigrants & 3.88 & .71 & 3.77 & .73 & 3.54 & .73 \\
& & & & & & & \\
Neutral & Natives & $3.75(\mathrm{ab})$ & .90 & $3.49(\mathrm{~b})$ & .95 & $3.43(\mathrm{ab})$ & .99 \\
Condition & Immigrants & 3.83 & .68 & 3.79 & .78 & 3.55 & .83 \\
& & & & & & & \\
Negative & Natives & $3.41(\mathrm{~b})$ & .81 & $3.37(\mathrm{~b})$ & .84 & $3.17(\mathrm{~b})$ & .87 \\
Priming & Immigrants & 3.88 & .63 & 3.73 & .63 & 3.50 & .76 \\
& & & & & & & \\
Total & Natives & 3.71 & .83 & 3.62 & .86 & 3.50 & .91 \\
& Immigrants & 3.87 & .67 & 3.77 & .72 & 3.52 & .77 \\
\hline
\end{tabular}

Note: Different letters indicate significant differences across priming conditions in native digitals sample

In addition, the findings showed that the interactions between the priming conditions and digital generations were significant for all three forms of prosocial behaviour [helping: $F(1,287)=3.60 \mathrm{p}<.05, \eta 2=.02$; sharing: $F(1,287)=3.16$ $\mathrm{p}<.01, \eta 2=.02$; and caring $\mathrm{F}(1,287)=3.00 \mathrm{p}=.05, \eta 2=.02]$. Specifically, as in the case of the overall prosocial score, the differences between positive and negative priming conditions were significant only for the native group. In addition, in the case of sharing, the control group scored lower than the positive priming group but was not different from the negative condition.

\subsubsection{Discussion}

The findings of this study confirmed the role of affective priming on prosocial orientation, when controlling for gender and country. Specifically, participants rated their level of prosocial orientation higher in this scale, when items were associated with images showing situations in which a helpee was supported by others and showed positive emotions, than participants in the negative priming condition. In addition, results showed that both digital natives and immigrants did not differ in their level of prosocial orientation. However, they differed on the role of affective priming on prosocial orientation. Indeed, while digital natives were influenced by the type of images associated with the items they were rating, the immigrants were not. This interaction was also confirmed when separately considering the different forms of prosocial behaviour (helping, sharing, and 
caring). Overall, these results confirmed that digital natives could be more susceptible to the influence of technologically mediated visual stimuli than digital immigrants.

\subsection{General Discussion}

In line with affective computing literature (Picard, 2003) the present research suggested that affective processes, even when activated through a mobile app (Isen, 2000; Skandrani-Marzouki et al., 2012), may play a key role in directing individuals prosocial orientation. Specifically, findings from the quasi-experiment highlighted that prosocial orientation is higher in the positive affective priming condition and lower in the negative affective priming condition. In other words, the affective activation elicited by the images and the prosocial orientation are consistent: images negatively activating individuals tend to result in a reduced prosocial orientation, on the contrary images positively activating individuals tend to result in an increased prosocial orientation. This effect is significant also after controlling for a socio-demographic factor as gender, and a cultural factor as national context that are relevant in relation to prosociality in a technological environment (Penner et al., 2005). This result is in line with the classical literature on priming underlining the impact of stimuli, according to which negative stimuli lead to an avoidance response while positive stimuli lead to an approaching behaviour (Hamm, Schupp, \& Weike, 2003; Lang, 1995). With particular reference to prosocial orientation it is likely that the presentation of images negatively connoted may recall participants about situations in which providing support implied the management of negative emotions, a condition people would usually refrain from (Bower, 1981). On the contrary, positive images are likely to recall participants about pleasant situations in which the positive affective activation fostered their propensity to provide support (Bieroff, 2008).

However, when considering digital generations, results showed that, although digital natives and immigrants did not significantly differ on prosocial orientation, only digital natives were influenced by manipulation of priming conditions. In agreement with the emerging literature on digital natives (Garner \& Davis, 2013; Jenkins, 2009) it is likely that the presence of visual stimuli played an essential role. Digital natives are particularly attracted by images (Presky, 2001) and may be more sensitive to the influence of the elicited affective activation (D'Errico et al., 2018). On the contrary, for digital immigrants it is likely that their greater proneness to pay attention to textual contents attenuated the effect of the affective priming elicited by images. In interpreting this specific result, it is also important to consider that in digital immigrants, being older, the prosocial orientation may be more stable across situations and less sensitive to external factors (Freund \& Blanchard, 2014). Hence digital immigrants may be mainly self-regulated in their prosocial orientation, while digital natives may be more externally-regulated, being still in a developmental stage of their identity. 
The significant interaction between affective priming and digital generations emerged for each form of prosocial orientation examined in the present contribution. This attests that, regardless of the specific type of required support (practical help, comfort, sharing), the way in which the request is affectively primed influences the digital natives' prosocial orientation. This has a relevant practical implication because the presence of external negative visual stimuli may involuntarily distance natives from a request for support. In this sense, the present findings could contribute to implementing a tailored system who takes into account individual's differences in visual information processing through mobile applications (Adams \& Hannaford, 1999). It is hence necessary, also in technologically mediated contexts, to identify strategies aimed to booster the development of emotional competences needed to manage the negative activation potentially associated to others' state of need. Indeed, the classical literature on the helping behaviour has always emphasised how the 'effective helper' (Paciello et al., 2013; D'Errico et al. 2010; Nadler, 2012) has the ability to manage at the same time their own emotions and others' difficulties.

There are a number of limitations in the present research that need to be acknowledged. First, a measure of the actual prosocial behaviour (or a proxy) was not included, leaving unexplored whether findings related to prosocial orientation can be indeed extended to individual conduct in real situations. Second, the app was freely downloadable and participants were completely unconstrained about when or when access it. As a result there was no control on the participants' responding conditions, and the impact of other external factors influencing responses cannot be excluded. Nevertheless, this can be indeed acknowledged as a general limit when data are collected via mobile applications (Bouwman et al., 2013). Third, the current version of the app does not allow researchers to keep track of response and reaction times or to assess other individual characteristics that can be relevant in relation to both prosocial orientation and priming. Future studies should explore these additional variables in order to strengthen the findings of the present research. Finally, the sample size is quite limited and it would be worthy to scale it up in future research. However, our sample included participants coming from two different geographical areas (Europe vs. North America). Notwithstanding the above mentioned limits, results are promising, and open up to further future investigations through innovative methodologies, particularly relevant for research on digital generations.

\section{Conclusion}

The digital revolution has produced changes not only in people habits but has also an influence on individuals' cognitive and affective processes. In the line of cognitive infocommunication research (Baranyi et al., 2015), and particularly in reference to affective computing research (Picard, 2003), we examined the effect of affective priming on prosocial orientation. Literature on technologically mediated environment has mainly focused the attention on bullying and cheating (Vandebosch \& Van Cleemput, 2008). A limited attention has been directed to 
explore the potential role of technology as a means to influence prosocial conduct, despite its importance for individual and communities. Using an app specifically developed for this research the study attested how the presence of affectively connoted images may exert an influence on individuals' orientation to help, share with and take care of others. Findings provide empirical evidence on the differences between digital natives and immigrants in relation to the influence of priming on prosocial orientation.

In the affective computing research field, this research contributes to understanding the interplay between affective technological cues and behavioral orientations. At the same time, it aims to highlighting the promotion of conscious filters for potential priming effects, especially in new generations. The app developed for the present study may provide innovative tool for future research. On one hand, the app represent a prototype that help to design future apps and technologies by taking into account the affective import of visual cues. On other hand, it may be used to further explore the role of affective images in unconscious influence as to regard prosocial behaviours.

\section{References}

[1] Adams, R.J. \& Hannaford, B. (1999). Stable haptic interaction with virtual environments. IEEE Transactions on Robotics and Automation, 15(3):465474

[2] Baranyi, P., \& Csapó, Á. (2012). Definition and synergies of cognitive infocommunications. Acta Polytechnica Hungarica, 9(1), 67-83

[3] Baranyi, P., Csapo, A., \& Sallai, G. (2015). Cognitive Infocommunications (CogInfoCom). Springer

[4] Batson, C. D., Fultz, J., \& Schoenrade, P. A. (1987). Distress and empathy: Two qualitatively distinct vicarious emotions with different motivational consequences. Journal of Personality, 55(1), 19-39

[5] Bebko, C., Sciulli, L. M., \& Bhagat, P. (2014). Using eye tracking to assess the impact of advertising appeals on donor behavior. Journal of Nonprofit \& Public Sector Marketing, 26(4), 354-371

[6] Bierhoff, H.W. (2008). Prosocial behaviour In: M. Hewstone, W. Stroebe, K. Jonas (eds) Introduction to Social Psychology. A European Perspective. London

[7] Bower, G. H. (1981). Mood and memory. American Psychologist, 36(2), 129

[8] Bouwman, H., de Reuver, M., Heerschap, N., \& Verkasalo, H. (2013). Opportunities and problems with automated data collection via smartphones. Mobile Media \& Communication, 1(1), 63-68

[9] Burt, C. D., \& Strongman, K. (2005). Use of images in charity advertising: Improving donations and compliance rates. International Journal of Organisational Behaviour, 8(8), 571-580 
[10] Caprara, G. V., Steca, P., Zelli, A., \& Capanna, C. (2005). A new scale for measuring adults' prosocialness. European Journal of Psychological Assessment, 21(2), 77-89

[11] Carlson, M., \& Miller, N. (1987). Explanation of the relation between negative mood and helping. Psychological Bulletin, 102(1), 91

[12] Carlson, M., Charlin, V., \& Miller, N. (1988). Positive mood and helping behavior: a test of six hypotheses. Journal of Personality and Social Psychology, 55(2), 211

[13] Chen, M., \& Bargh, J. A. (1997). Nonconscious behavioral confirmation processes: The self-fulfilling consequences of automatic stereotype activation. Journal of Experimental Social Psychology, 33(5), 541-560

[14] Cohen, E. L. (2014). What makes good games go viral? The role of technology use, efficacy, emotion and enjoyment in players' decision to share a prosocial digital game. Computers in Human Behavior, 33, 321-329

[15] D'Errico, F., Leone, G., \& Poggi, I. (2010). Types of help in the teacher's multimodal behavior. In Proceedings of Human Behavior Understanding (pp. 125-139). Springer Berlin Heidelberg

[16] D'Errico, F., Paciello, M., De Carolis, B., Vattani, A., Palestra, G., \& Anzivino, G. (2018). Cognitive Emotions in E-Learning Processes and Their Potential Relationship with Students' Academic Adjustment. International Journal of Emotional Education, 10(1), 89-111

[17] Ferri, P. (2011). Nativi digitali. B. Mondadori. Milano

[18] Forgas, J. P. (2007). When sad is better than happy: Negative affect can improve the quality and effectiveness of persuasive messages and social influence strategies. Journal of Experimental Social Psychology, 43(4), 513-528

[19] Freund, A. M., \& Blanchard-Fields, F. (2014). Age-related differences in altruism across adulthood: Making personal financial gain versus contributing to the public good. Developmental Psychology, 50(4), 1125

[20] Gardner, H., \& Davis, K. (2013). The app generation: How today's youth navigate identity, intimacy, and imagination in a digital world. Yale University Press

[21] Gentile, D. A., Anderson, C. A., Yukawa, S., Ihori, N., Saleem, M., Ming, L. K., \& Huesmann, L. R. (2009). The effects of prosocial video games on prosocial behaviors: International evidence from correlational, longitudinal, and experimental studies. Personality and Social Psychology Bulletin, 35(6), 752-763

[22] Greenwald, A. G., Draine, S. C., \& Abrams, R. L. (1996). Three cognitive markers of unconscious semantic activation. Science, 273(5282), 1699

[23] Greitemeyer, T., \& Osswald, S. (2009). Prosocial video games reduce aggressive cognitions. Journal of Experimental Social Psychology, 45(4), 896-900 
[24] Isen, A. M. (2000). Some perspectives on positive affect and selfregulation. Psychological Inquiry, 11(3), 184-187

[25] Leone, G. (2012). Observing social signals in scaffolding interactions: how to detect when a helping intention risks falling short. Cognitive Processing, 13(2), 477-485

[26] Lebart, L., Salem, A. \& Berry, L. (1998). Exploring textual data. Kluwer Academic Publishers

[27] Jenkins, H. (2006). Convergence culture: Where old and new media collide. NYU press

[28] Jenkins, H., Purushotma, R., Weigel, M., Clinton, K., \& Robison, A. J. (2009). Confronting the challenges of participatory culture: Media education for the 21st century. Mit Press

[29] Klauer, K. C., \& Musch, J. (2003). Affective priming: Findings and theories. The Psychology of Evaluation: Affective Processes in Cognition and Emotion, 7-49

[30] Hamm, A. O., Schupp, H. T., \& Weike, A. I. (2003). Motivational organization of emotions: Autonomic changes, cortical responses, and reflex modulation. Handbook of affective sciences, 187-211

[31] Lang, P. J. (1995). The emotion probe: Studies of motivation and attention. American Psychologist, 50(5), 372

[32] Lennon, R., Rentfro, R., \& O'Leary, B. (2010). Social marketing and distracted driving behaviors among young adults: The effectiveness of fear appeals. Academy of Marketing Studies Journal, 14(2), 95

[33] Nadler, A. (2012). From help-giving to helping relations: Belongingness and independence in social interaction. Deaux K, Snyder Meditors. The Oxford Handbook of Personality and Social Psychology, 1, 394-418

[34] Nilsson, M., Johansson, S., \& Håkansson, M. (2003, April). Nostalgia: an evocative tangible interface for elderly users. In CHI'03 Extended Abstracts on Human Factors in Computing Systems (pp. 964-965). ACM

[35] Norman, D. A. (2004). Emotional Design: Why We Love (or Hate) Everyday Things. New York: Basic Books

[36] Paciello, M., Fida, R., Cerniglia, L., Tramontano, C., \& Cole, E. (2013). High cost helping scenario: The role of empathy, prosocial reasoning and moral disengagement on helping behavior. Personality and Individual Differences, 55(1), 3-7

[37] Penner, L. A., Dovidio, J. F., Piliavin, J. A., \& Schroeder, D. A. (2005). Prosocial behavior: Multilevel perspectives. Annual Review Psychology, 56, 365-392

[38] Palfrey, J., Gasser, U. (2008). Born digital: Understanding the first generation of digital natives. New York: Basic Books 
[39] Picard, R. W. (2003). Affective computing: challenges. International Journal of Human-Computer Studies, 59(1-2), 55-64

[40] Prensky, M. (2009). H. Sapiens Digital: From Digital Immigrants and Digital Natives to Digital Wisdom. Journal of Online Education, 5(3)

[41] Prensky, M. (2001a). Digital Natives, Digital Immigrants : Part 1. On the Horizon, 9(5), 1-6

[42] Prensky, M. (2001b). Digital Natives, Digital Immigrants Part 2: Do they really think differently? On the Horizon, 9(6), 1-6

[43] Prot, S., Gentile, D. A., Anderson, C. A., Suzuki, K., Swing, E., Lim, K. M., ... \& Liau, A. K. (2014). Long-term relations among prosocial-media use, empathy, and prosocial behavior. Psychological Science, 25(2), 358368

[44] Rosenhan, D. L., Salovey, P., \& Hargis, K. (1981). The joys of helping: Focus of attention mediates the impact of positive affect on altruism. Journal of Personality and Social Psychology, 40(5), 899

[45] Skandrani-Marzouki, I., Marzouki, Y., \& Joule, R. V. (2012). Effects of subliminal affective priming on helping behavior using the foot-in-the-door technique. Psychological Reports, 111(3)

[46] Shaffer, D. R., \& Graziano, W. G. (1983). Effects of positive and negative moods on helping tasks having pleasant or unpleasant consequences. Motivation and Emotion, 7(3), 269-278

[47] Shin, Y., Lee, B., \& Kim, J. (2015). Prosocial Activists in SNS: The Impact of Isomorphism and Social Presence on Prosocial Behaviors. International Journal of Human-Computer Interaction, 31(12), 939-958

[48] Sinclair, R. C., \& Mark, M. M. (1995). The effects of mood state on judgemental accuracy: Processing strategy as a mechanism. Cognition \& Emotion, 9(5), 417-438

[49] Wright, M. F., \& Li, Y. (2011). The associations between young adults' face-to-face prosocial behaviors and their online prosocial behaviors. Computers in Human Behavior, 27(5), 1959-1962

[50] Tan, H. B., \& Forgas, J. P. (2010). When happiness makes us selfish, but sadness makes us fair: Affective influences on interpersonal strategies in the dictator game. Journal of Experimental Social Psychology, 46(3), 571576

[51] Vandebosch, H., \& Van Cleemput, K. (2008). Defining cyberbullying: A qualitative research into the perceptions of youngsters. CyberPsychology \& Behavior, 11(4), 499-503

[52] Vinciarelli, A., Pantic, M., Heylen, D., Pelachaud, C., Poggi, I., D'Errico, F., \& Schroeder, M. (2012). Bridging the gap between social animal and unsocial machine: A survey of social signal processing. IEEE Transactions on Affective Computing, 3(1), 69-87 